\title{
əEvaluation of GPM Dual-Frequency Precipitation Radar (DPR) Rainfall Products Using the Rain Gauge Network over China
}

\author{
YANG GaO, ${ }^{\mathrm{a}}$ TONGWEN Wu, ${ }^{\mathrm{b}}$ Jun WANG, ${ }^{\mathrm{c}}$ AND ShIHAO TANG ${ }^{\mathrm{a}}$ \\ ${ }^{a}$ National Satellite Meteorological Center, China Meteorological Administration, Beijing, China \\ ${ }^{\mathrm{b}}$ Beijing Climate Center, China Meteorological Administration, Beijing, China \\ ${ }^{\mathrm{c}}$ Department of Chemical and Biochemical Engineering, The University of Iowa, Iowa City, Iowa
}

(Manuscript received 29 June 2020, in final form 3 December 2020)

\begin{abstract}
The Dual-Frequency Precipitation Radar (DPR) on board the Global Precipitation Measurement (GPM) mission core satellite provides the new-generation global observation of rain since 2014. The main objective of this paper is to evaluate the suitability and limitation of GPM-DPR level-2 products over China. The DPR rain rate products are compared with rain gauge data during the summers of 5 years (2014-18). The ground observation network is composed of more than 50000 rain gauges. The DPR precipitation products for all scans (DPR_NS, DPR_MS, and DPR_HS) generally underestimate rain rates. However, DPR_MS agrees better with gauge estimates than DPR_NS and DPR_HS, yielding the lowest mean error, systematic deviation, and highest Pearson correlation coefficient. In addition, all three swath types show obvious overestimation over gauge estimates between 0.5 and $1 \mathrm{~mm} \mathrm{~h}^{-1}$ and underestimation when gauge estimates are larger than $1 \mathrm{~mm} \mathrm{~h}^{-1}$. The DPR_HS and DPR_MS agree better with gauge estimates below and above $2.5 \mathrm{~mm} \mathrm{~h}^{-1}$, respectively. A deeper investigation was carried out to analyze the variation of DPR_MS's performance with respect to terrains over China. An obvious underestimation, relative to gauge estimates, occurs in Tibetan Plateau while a slight overestimation occurs in the North China Plain. Furthermore, our comprehensive analysis suggests that in Sichuan Basin, the DPR_MS exhibit the best agreement with gauge estimates.
\end{abstract}

KEYWORDS: Radars/Radar observations; Remote sensing; Satellite observations

\section{Introduction}

Precipitation plays an indispensable role in Earth's water and energy cycle. In recent decades, while rain gauges are widely used in precipitation measurement, it is still difficult to obtain accurate and comprehensive precipitation information at multiple spatial and temporal scales. The distribution of rain gauges is usually affected by underlying surface. For example, the Tibetan Plateau is a region with complex terrain and sparse ground-based measurements. In addition, the observation data are extremely sparse over the ocean. Therefore, utilizing the satellite precipitation products has enjoyed an increasing trend in recent years, especially over the area with limited rain gauges.

Started in 1997, the Tropical Rainfall Measuring Mission (TRMM) was the first ever satellite that combined the active and passive instruments to provide important measurements of medium and heavy rainfall in the tropical and subtropical regions of our Earth. Compared to the passive sensors, an active sensor like Precipitation Radar (PR) can provide the intensity and distribution of rain, particularly the three-dimensional rain structure. On 15 April 2015, however, TRMM stopped working after its fuel was depleted.

Building upon the success of the TRMM, the Global Precipitation Measurement (GPM) mission provides a newgeneration global observations of rain. The core observatory of

¿ Denotes content that is immediately available upon publication as open access.

Corresponding author: Tongwen Wu,twwu@cma.gov.cn
GPM was initiated by the U.S. National Aeronautics and Space Administration and the Japan Aerospace Exploration Agency, and was launched on 27 February 2014 (Hou et al. 2014). It carries the first spaceborne Dual-Frequency Precipitation Radar (DPR), which consists of a Ka-band precipitation radar (KaPR) operating at $35.5 \mathrm{GHz}$ and a $\mathrm{Ku}$-band precipitation radar (KuPR) operating at $13.6 \mathrm{GHz}$. The DPR is more sensitive to light rain than the PR on board TRMM (Hamada and Takayabu 2016). In addition, GPM's spatial coverage between $65^{\circ} \mathrm{N}$ and $65^{\circ} \mathrm{S}$ is greater than that of TRMM. Thus, GPM is expected to provide unprecedented measurements for studying the characteristics of global precipitation.

Many evaluations of the GPM precipitation products have been carried out in recent years. Several studies about level-3 Integrated Multisatellite Retrievals for GPM data have shown that the product is suitable to be used in different countries and complex surface conditions. These studies show that the level-3 products at different temporal scales from hourly and daily to monthly are able to capture the precipitation intensity and coverage reasonably well when compared with the rain gauges and ground-based radars (Guo et al. 2016; Tan and Duan 2017; Mahmud et al. 2017; Yuan et al. 2017; Lu et al. 2018; Zhang et al. 2018; Sun et al. 2018; Ma et al. 2019; Maghsood et al. 2020; $\mathrm{Yu}$ et al. 2020). The focus in most of past studies is the level-3 gridded satellite products that are merged by using the data from many satellite instruments and precipitation gauge analyses.

Recently, a few attempts were also made to evaluate level-2 products. Gao et al. (2017) pointed out that GPM level-2 DPR products are more sensitive at detecting light precipitation and better at type classification than TRMM. Besides, compared with the Cloud Profiling Radar on board CloudSat, DPR has 
(a) 2014

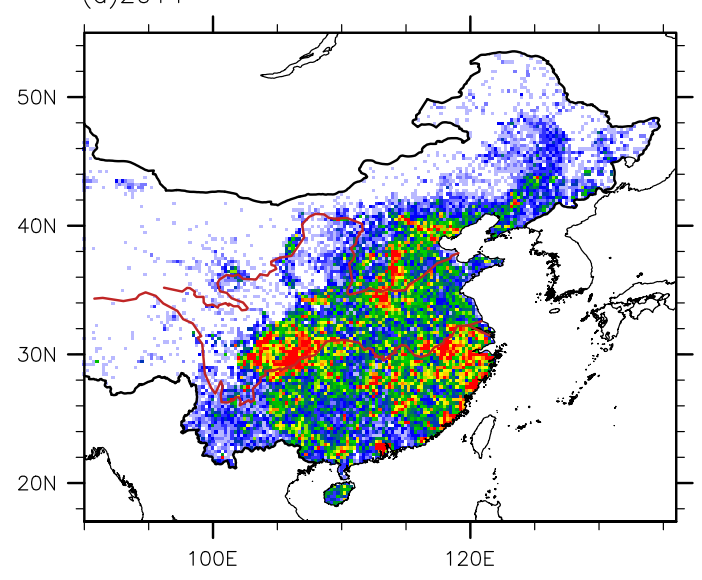

(b) 2018

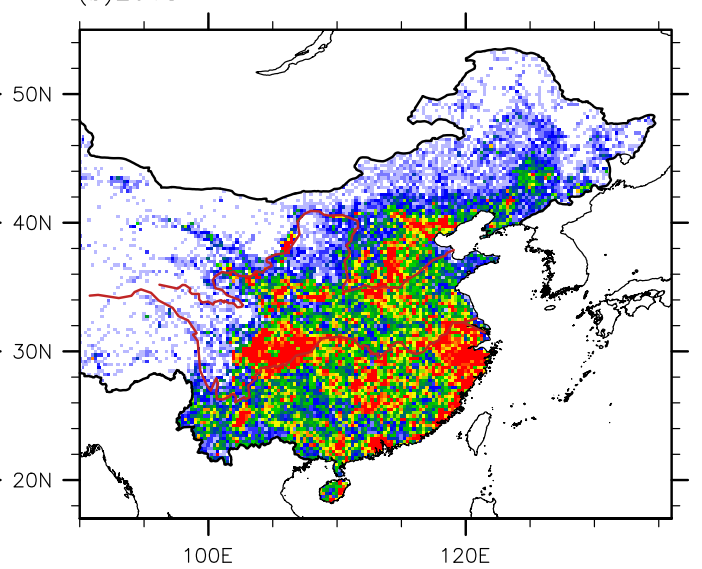

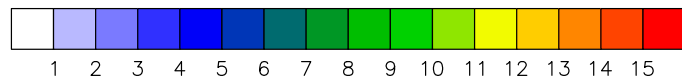

FIG. 1. The number of ground-based rain gauges at $0.25^{\circ} \times 0.25^{\circ}$ resolution in 2014 and 2018 .

an advantage of measuring higher snowfall rates although its accuracy needs to be improved further (Tang et al. 2017; Casella et al. 2017). Zhang and Fu (2018) have analyzed the similarities and differences of level-2 products through four precipitation cases. They found that the precipitation and droplet size distribution of typhoon eyewall from DPR_MS are more reasonable than the $\mathrm{Ka}$ - and $\mathrm{Ku}$-band products. In addition, some studies focused on assessing the suitability of using level-2 products in the different countries. For instance, Petracca et al. (2018) showed that the level-2 DPR precipitation rates agree better with ground-based estimates than the single Ka-band or Ku-band product over Italy. Speirs et al. (2017) found that, relative to ground-based estimates, the detection and estimation performance of DPR measurements vary with seasons and terrains in Switzerland. However, due to its short time in operation, the attempts to evaluate GPM level-2 products are relatively limited.

The level-2 products are important to the generation of level-3 products. Moreover, they can provide the vertical structure and more details of the precipitation system as TRMM did (L'Ecuyer and McGarragh 2010; Hence and Houze 2012; Bhat and Kumar 2015). Therefore, evaluation of level-2 product is the main focus of this study. To our knowledge, there is no comprehensive investigation that evaluates the performance of GPM level-2 products over China, which can be viewed as an ideal test bed due to its wide range of surface conditions and its complex terrain and topography including the Tibetan Plateau, Sichuan Basin, and Yangtze Plain. Therefore, to better utilize the GPM level-2 products, we will compare the DPR precipitation rate products with the dense rain gauge network over China. The results cannot only provide insights into the potentials and limitations of GPM level-2 products but also offer useful information toward the improvement of retrieval algorithms in the future.

The paper is arranged as follows. In section 2, a brief description of GPM-DPR precipitation rate data and the methodology used are presented. In section 3, the results are shown by comparing GPM with rain gauges, while in section 4, summary and conclusions are reported.

\section{Data and methodology}

An important instrument on board the GPM Core Observatory for rain rate measurements is the DPR. The DPR consists of a $\mathrm{Ku}$-band $(13.6 \mathrm{GHz})$ precipitation radar that is an updated version of TRMM's PR, while its Ka band $(35.5 \mathrm{GHz})$ is used to remedy some weaknesses of the $\mathrm{Ku}$ band. The uncertainty in rainfall estimates associated with the single-band TRMM PR is rooted in its limited one-frequency sampling of the spectrum of droplet size distribution (DSD). The inclusion of a higherfrequency Ka band in GPM's DPR provides an additional sampling in the non-Rayleigh scattering regime and hence another mostly independent piece of information for the retrievals of DSD. Therefore, Ku together with the new Ka-band channel can provide more accurate estimates of rainfall rate (Iguchi et al. 2010). KuPR's scan has 49 footprints and a scan swath of $\sim 245 \mathrm{~km}$, similar to those TRMM's PR. KaPR's scan can be divided into two types: one is the matched scan (MS) when the KaPR's beams match the KuPR's with a swath of $120 \mathrm{~km}$; another is the high-sensitivity scan (HS) when the KaPR's beams are interlaced within the matched beams. The footprints of $\mathrm{Ka}$ and $\mathrm{Ku}$ bands are both $\sim 5.2-\mathrm{km}$ diameter.

In this paper, we used the $2 \mathrm{~A}-\mathrm{DPR}$ product during the summers (June-August) of 2014-18, which is based on the dual-frequency algorithm. The summer data of 5 years can provide sufficient statistical samples. There are three types of swath in the level-2 version 06A product of 2A-DPR: DPR_NS for normal scan, DPR_MS for matched scan, and DPR_HS for high-sensitivity scan. All of them provide estimates of surface precipitation rates (precipRateESurface) classified into three categories: stratiform, convective, and other (Awaka et al. 2016). However, as the DPR has changed its scan pattern since 21 May 2018, DPR_HS swath type is no longer available after June 2018 in the current product. 
The hourly precipitation of ground-based rain gauge data during 2014-18 were collected at more than 50000 stations in China, which are provided by the National Meteorological Information Center, China Meteorological Administration. To obtain the sufficient samples, the rain gauge data were collected by national-level and regional-level automatic weather stations. These data have proven to be credible, and used in the studies of precipitation characteristics (Shen et al. 2010, 2014). The study area in this paper focuses on the east of $90^{\circ} \mathrm{E}$, because the distribution of rain gauge in western China is sparse due to local topography and population density. Figure 1 shows the spatial distribution of rain gauges at $0.25^{\circ} \times 0.25^{\circ}$ resolution. The number density has a growing trend from 2014 to 2018 . We also performed a separate analysis on those samples for single year, finding that the results are consistent with results from the 5 years of samples. Therefore, the changes in rain gauges density in these years do not affect the results.

Taking into account the diameter of DPR's pixel size, we set the pairing criterion that a DPR pixel matches with a rain gauge at better than $0.02^{\circ}$ in both latitude and longitude. On the other hand, if a DPR pixel matches with more than one rain gauge, all data of rain gauges are averaged. The satellite-based retrieval of precipitation is instantaneous in nature while the hourly data of rain gauge are accumulated. Therefore, the hourly precipitation of rain gauge data is interpolated to the scanning time of the GPM overpass. For instance, if the accumulated precipitation is $X \mathrm{~mm}$ between 0100 and 0200 local time (LT) and $Y \mathrm{~mm}$ between 0200 and $0300 \mathrm{LT}$, then the rain rates are regarded as $X \mathrm{~mm} \mathrm{~h}^{-1}$ at $0130 \mathrm{LT}$ and $Y \mathrm{~mm} \mathrm{~h}^{-1}$ at $0230 \mathrm{LT}$. If the GPM overpass time is between 0130 and $0230 \mathrm{LT}$, the gauge estimates rain rate is linearly interpolated by using $X \mathrm{~mm} \mathrm{~h}^{-1}$ and $Y \mathrm{~mm} \mathrm{~h}^{-1}$. Thus, the precipitation rate from DPR at the pixel level can be paired with a value from rain gauge at one point. Petracca et al. (2018) used half-hour accumulated rain gauge data and interpolated to $1 \mathrm{~km} \times 1 \mathrm{~km}$ to evaluate GPM-DPR products. However, this interpolation also brings additional uncertainties. Therefore, currently there seems to be no better ground-based rain gauge data compared to satellite instantaneous precipitation, our temporal-spatial matching method is a new attempt to evaluate GPM-DPR products.

To consider the complexity in the pixel-to-point comparison and evaluation, five widely used statistical metrics were applied to evaluate the GPM-DPR's products, including the Pearson correlation coefficient (CC), root-mean-square error (RMSE), mean error $(\mathrm{ME})$, standard deviation $(\sigma)$, and the coefficient of variation $(\mathrm{CV})$. In particular, the percentage error $(\mathrm{PE})$ is also used to evaluate the GPM satellite products in order to analyze the systematic deviation. The equations of the indicators are as follows:

$$
\begin{aligned}
\mathrm{CC} & =\frac{\sum_{i=1}^{n}\left(S_{i}-\bar{S}\right)\left(G_{i}-\bar{G}\right)}{\sqrt{\sum_{i=1}^{n}\left(S_{i}-\bar{S}\right)^{2}} \sqrt{\sum_{i=1}^{n}\left(G_{i}-\bar{G}\right)^{2}}}, \\
\mathrm{RMSE} & =\sqrt{\frac{\sum_{i=1}^{n}\left(S_{i}-G_{i}\right)^{2}}{n}},
\end{aligned}
$$

(a)DPR_MS vs rain gauge

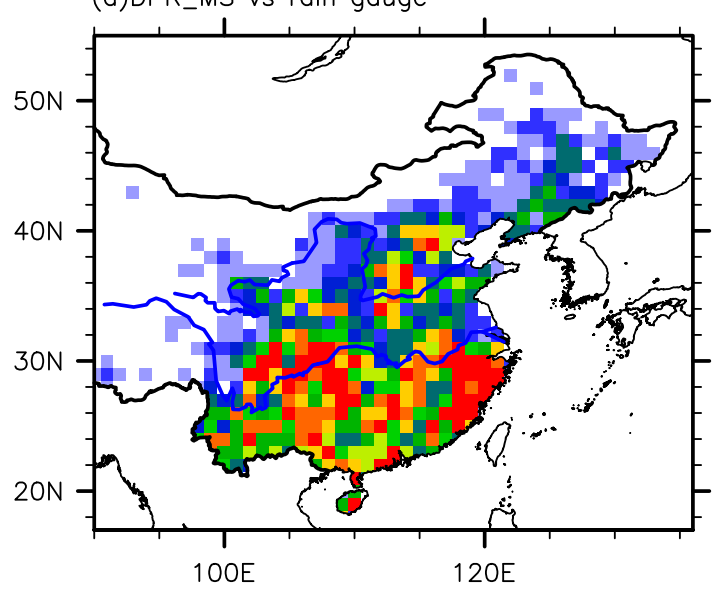

(b)DPR_NS vs rain gauge

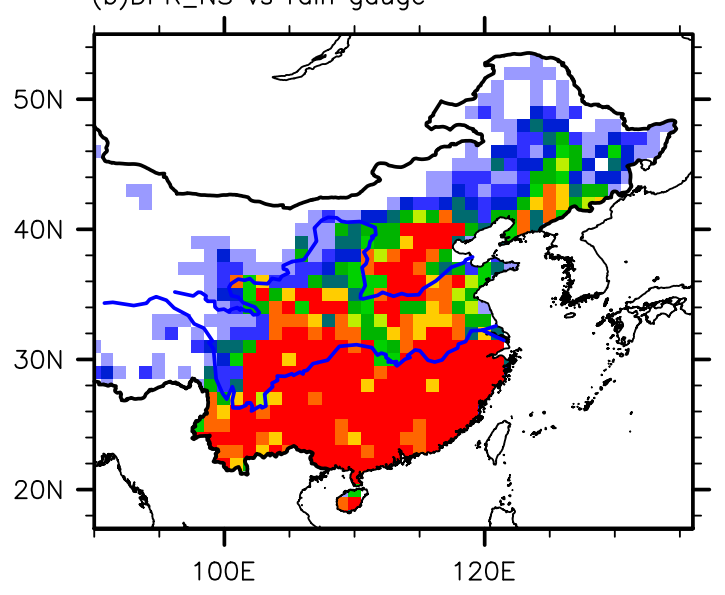

(c)DPR_HS vs rain gauge
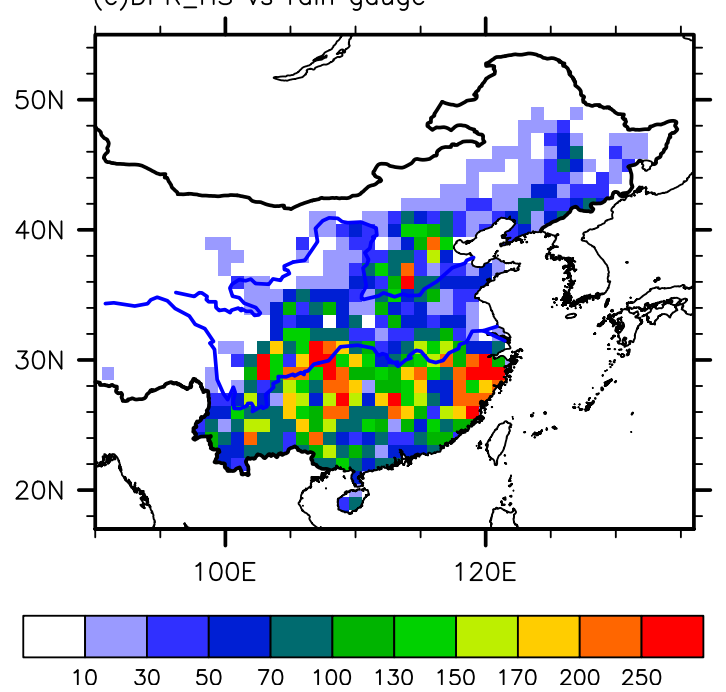

FIG. 2. Spatial distribution of matched samples between DPR estimated surface precipitation products and ground-based rain gauges at $1^{\circ} \times 1^{\circ}$ resolution during the summer (June-August), (a) DPR_MS and rain gauges from 2014 to 2018, (b) DPR_NS and rain gauges from 2014 to 2018, (c) DPR_HS and rain gauges from 2014 to 2017. 

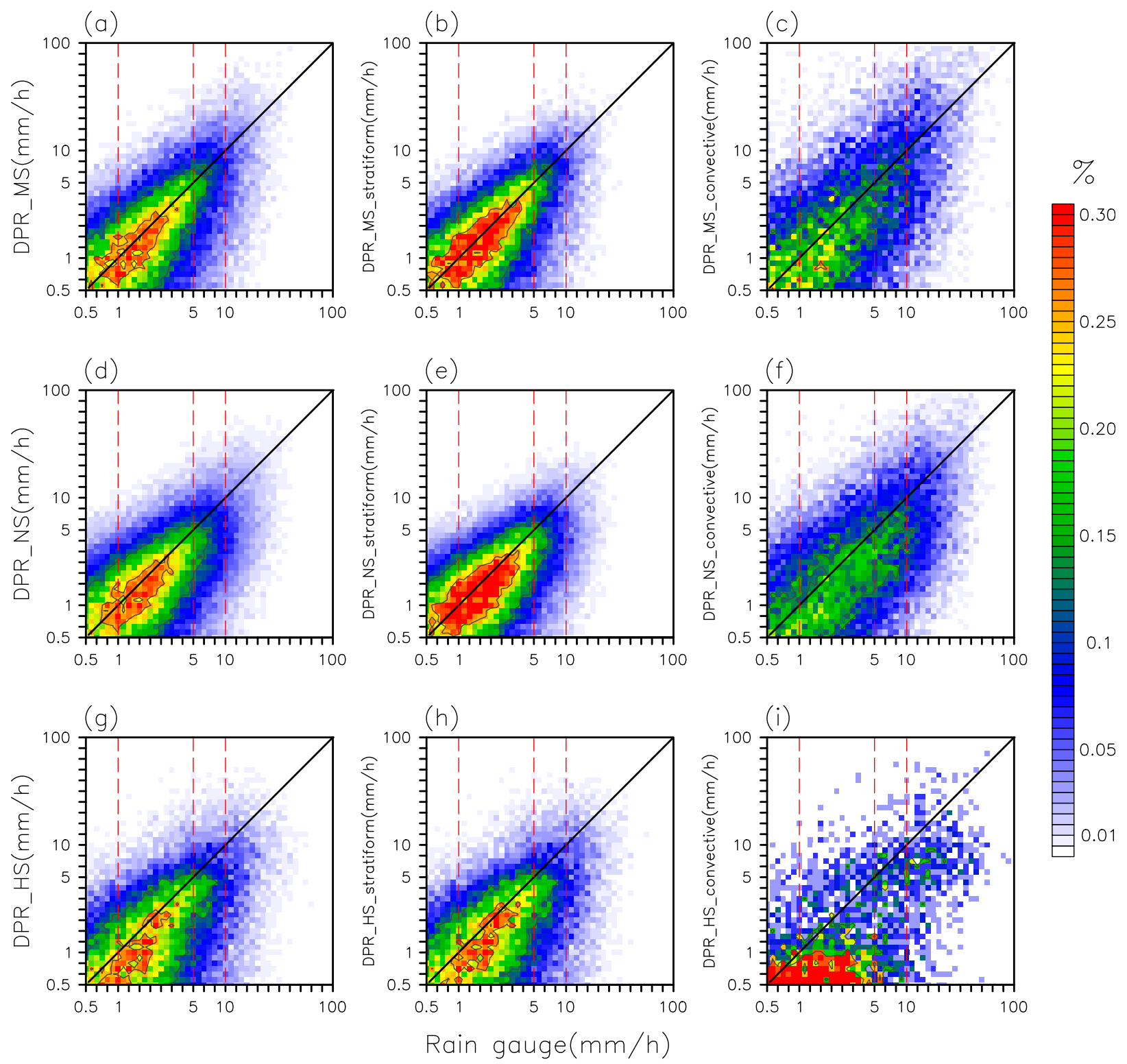

FIG. 3. Density scatterplots for the GPM estimated surface precipitation products for (a)-(c) DPR_MS, (d)-(f) DPR_NS, and (g)-(i) DPR_HS vs the corresponding rain gauges data. The left, center, and right columns represent all samples of total, stratiform, and convective precipitation, respectively. The occurrence frequency represents the percentage with respect to the total samples of the number (all samples, stratiform precipitation samples, and convective precipitation samples, respectively) lying in each grid area with an interval of $10^{0.05} \mathrm{~mm} \mathrm{~h}^{-1}$. The color bar indicates the occurrence frequency (\%) lying within each grid area. The black line is the $1: 1$ line.

$$
\begin{aligned}
\mathrm{ME} & =\frac{\sum_{i=1}^{n}\left(S_{i}-G_{i}\right)}{n}, \\
\sigma & =\sqrt{\frac{\sum_{i=1}^{n}\left(S_{i}-\bar{S}\right)^{2}}{n},} \\
\mathrm{CV} & =\frac{\sigma}{\bar{S}},
\end{aligned}
$$

$$
\mathrm{PE}_{i}=\frac{S_{i}-G_{i}}{G_{i}} \times 100 \%,
$$

where $n$ is the number of matched samples, $S_{i}$ is the DPR estimated surface precipitation, $G_{i}$ represents interpolated rain gauge precipitation, and $\bar{S}$ and $\bar{G}$ are their mean values, respectively.

In addition, a threshold of minimum measurable rainfall rate of $0.2 \mathrm{~mm} \mathrm{~h}^{-1}$ is applied to Ka band and $0.5 \mathrm{~mm} \mathrm{~h}^{-1}$ for $\mathrm{Ku}$ band. To evaluate the 2A-DPR precipitation product, $0.5 \mathrm{~mm} \mathrm{~h}^{-1}$ was defined as a threshold in this paper. 
TABLE 1. Statistical metrics for the DPR estimated surface precipitation products computed with respect to rain gauges. The numbers of points are the matchups of the DPR pixel products with the ground-based rain gauges. The best value is bolded for each cell.

\begin{tabular}{|c|c|c|c|c|}
\hline & \multirow[b]{2}{*}{ Products } & \multicolumn{3}{|c|}{ Precipitation } \\
\hline & & Total & Stratiform & Convective \\
\hline \multirow[t]{3}{*}{ No. of points } & DPR_MS & 64006 & 47064 & 16822 \\
\hline & DPR_NS & 123741 & 90625 & 32995 \\
\hline & DPR_HS & 37794 & 34507 & 3253 \\
\hline \multirow[t]{3}{*}{ Percentage of stratiform or convective (\%) } & DPR_MS & $100 \%$ & $73.53 \%$ & $26.28 \%$ \\
\hline & DPR_NS & $100 \%$ & $73.24 \%$ & $26.66 \%$ \\
\hline & DPR_HS & $100 \%$ & $91.30 \%$ & $8.6 \%$ \\
\hline \multirow[t]{3}{*}{ Mean error $\left(\mathrm{mm} \mathrm{h}^{-1}\right)$} & DPR_MS & -0.075 & -0.23 & 0.38 \\
\hline & DPR_NS & -0.62 & -0.59 & -0.69 \\
\hline & DPR_HS & -1.25 & -1.11 & -2.7 \\
\hline \multirow[t]{3}{*}{ Root-mean-square error $\left(\mathrm{mm} \mathrm{h}^{-1}\right)$} & DPR_MS & 6.0 & 4.04 & 9.51 \\
\hline & DPR_NS & 5.7 & 3.77 & 9.09 \\
\hline & DPR_HS & 5.51 & 5.19 & 8.04 \\
\hline \multirow[t]{3}{*}{ Pearson correlation coefficient } & DPR_MS & 0.50 & 0.48 & 0.49 \\
\hline & DPR_NS & 0.48 & 0.45 & 0.45 \\
\hline & DPR_HS & 0.40 & 0.39 & 0.47 \\
\hline
\end{tabular}

\section{Results}

\section{a. Evaluation of the three types of $2 A-D P R$ swath}

Figure 2 shows the spatial distribution of the samples for each swath type of $2 \mathrm{~A}-\mathrm{DPR}$ pixels matched with the groundbased rain gauges. The number of matched pairs is different due to the difference in scan swath. We note that there are only four summers of DPR_HS instead of five, for it has been missing since June 2018 from the 2A-DPR product. The number of matchups is the largest for DPR_NS while the smallest in DPR_HS. Moreover, the sparse rain gauges and climatic characteristics of drought in the Tibetan Plateau and the northwest China can lead to the smaller number of matched pixels. Focusing on the similarities between three swath types, there are more matchups in southern China where the frequency of precipitation events and the number of rain gauges are higher in summer.

Figure 3 illustrates the density scatterplots for the GPM precipitation products and rain gauge. All three swath types (Figs. 3a,d,g) show a general underestimation for rain rate. Both DPR_MS and DPR_NS swath types perform better than DPR_HS, with DPR_MS having higher percentage of points near the 1:1 line than DPR_NS, in particular when the rain rate reaches above $5 \mathrm{~mm} \mathrm{~h}^{-1}$. Figure 3 also shows the rain type classification results for the matched samples. It is observed that there is higher percentage of matched samples near the

TABLE 2. The standard deviation $\left(\mathrm{mm} \mathrm{h}^{-1}\right)$ and coefficient of variation (\%) for DPR estimated surface precipitation products for different intensity intervals; $G_{i}$ represents interpolated rain gauge precipitation.

\begin{tabular}{|c|c|c|c|c|c|c|c|}
\hline \multirow[b]{2}{*}{ Precipitation } & \multirow[b]{2}{*}{ Products } & \multicolumn{6}{|c|}{$G_{i}\left(\mathrm{~mm} \mathrm{~h}^{-1}\right)$} \\
\hline & & $0.5-1$ & $1-2.5$ & $2.5-5$ & $5-10$ & 10-20 & $20-100$ \\
\hline \multirow[t]{6}{*}{ Total } & \multirow[t]{2}{*}{ DPR_MS } & 2.19 & 2.71 & 4.23 & 7.45 & 12.58 & 20.33 \\
\hline & & $140.3 \%$ & $125.0 \%$ & $116.4 \%$ & $116.4 \%$ & $116.2 \%$ & $105.8 \%$ \\
\hline & \multirow[t]{2}{*}{ DPR_NS } & 1.99 & 2.34 & 3.70 & 6.27 & 10.83 & 17.70 \\
\hline & & $128.2 \%$ & $114.4 \%$ & $113.6 \%$ & $117.3 \%$ & $121.6 \%$ & $111.6 \%$ \\
\hline & \multirow[t]{2}{*}{ DPR_HS } & 1.53 & 2.12 & 3.58 & 5.25 & 7.71 & 8.82 \\
\hline & & $105.0 \%$ & $109.7 \%$ & $120.1 \%$ & $115.0 \%$ & $111.8 \%$ & $94.84 \%$ \\
\hline \multirow[t]{6}{*}{ Stratiform } & \multirow[t]{2}{*}{ DPR_MS } & 1.83 & 1.84 & 3.02 & 5.54 & 9.28 & 13.01 \\
\hline & & $127.4 \%$ & $92.4 \%$ & $90.8 \%$ & $97.1 \%$ & $103.7 \%$ & $105.3 \%$ \\
\hline & \multirow[t]{2}{*}{ DPR_NS } & 1.55 & 1.57 & 2.60 & 4.59 & 7.78 & 11.15 \\
\hline & & $109.0 \%$ & $83.7 \%$ & $88.0 \%$ & $98.1 \%$ & $110.9 \%$ & $109.6 \%$ \\
\hline & \multirow[t]{2}{*}{ DPR_HS } & 1.56 & 2.10 & 3.57 & 5.25 & 7.59 & 8.30 \\
\hline & & $103.7 \%$ & $107.0 \%$ & $117.7 \%$ & $113.7 \%$ & $111.1 \%$ & $93.0 \%$ \\
\hline \multirow[t]{6}{*}{ Convective } & \multirow[t]{2}{*}{ DPR_MS } & 3.07 & 4.65 & 6.71 & 10.30 & 15.0 & 21.92 \\
\hline & & $154.5 \%$ & $163.2 \%$ & $144.1 \%$ & $130.1 \%$ & $117.5 \%$ & $100.5 \%$ \\
\hline & \multirow[t]{2}{*}{ DPR_NS } & 3.13 & 4.12 & 5.88 & 8.42 & 12.69 & 18.96 \\
\hline & & $150.4 \%$ & $148.2 \%$ & $137.6 \%$ & $128.2 \%$ & $120.0 \%$ & $107.3 \%$ \\
\hline & \multirow[t]{2}{*}{ DPR_HS } & 1.24 & 2.31 & 3.44 & 5.05 & 8.67 & 10.19 \\
\hline & & $107.8 \%$ & $149.9 \%$ & $160.5 \%$ & $129.5 \%$ & $114.0 \%$ & $96.6 \%$ \\
\hline
\end{tabular}



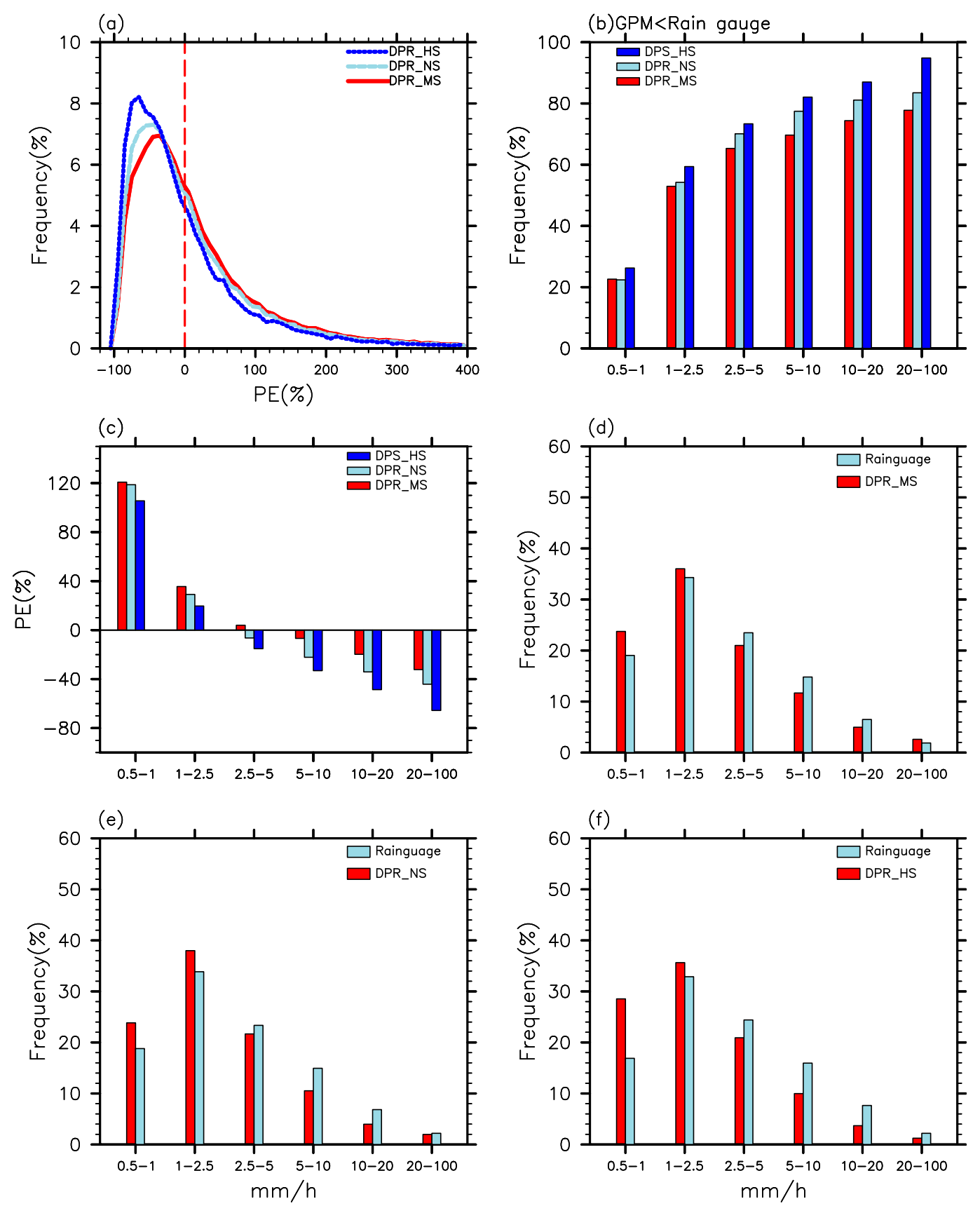

FIG. 4. (a) The PE for estimated surface precipitation of DPR_MS, DPR_NS, and DPR_HS in comparison with rain gauge; the interval of $\mathrm{PE}$ is $20 \%$ on the horizontal axis. (b) The frequency when the three swath types underestimate the rain rates for different intensity intervals, (c) the mean percentage error of the three DPR swath types, and (d)-(f) the occurrence frequency of different rain rate intensity intervals from DPR products and rain gauge.

1:1 line in the stratiform category than in convective category. For all three swath types, the distribution of stratiform samples is similar to that of the total. DPR_MS shows better performance in both stratiform and convective categories, while DPR_HS shows remarkable underestimation for rain rate. As shown in Fig. 3, the deviation of the satellite-based convective precipitation estimates from the ground-based observation increases with the rain rate. On the whole, we conclude that DPR_MS compares more favorably with rain gauge than the other two swath types.

Further statistical analysis was conducted based on the metrics introduced in section 2 and the results are shown in 
Table 1. The number of matched samples for DPR_NS is several times larger than those for DPR_MS and DPR_HS, not only because of larger scan swath, but also because of the lack of DPR_HS in 2018. The best results are shown in bold in Table 1. The DPR_MS swath type obtains the lowest ME and the highest CC when compared to the DPR_NS and DPR_HS. However, the RMSE of DPR_HS is slightly lower in all samples and convective samples. A deeper statistical analysis is conducted with respect to rain intensity. The standard deviation and CV for DPR estimated surface precipitation for different intensity intervals are shown in Table 2. In general, the standard deviation increases with precipitation intensity. For all three swath types, the standard deviation of DPR_HS in different intensities of the total samples and convective samples is lower than those for DPR_MS and DPR_NS. The CV of DPR_HS in all samples is the highest from 2.5 to $5.0 \mathrm{~mm} \mathrm{~h}^{-1}$ among the three swath types, while at other intensity intervals it is the smallest. In the range of $2.5-5.0 \mathrm{~mm} \mathrm{~h}^{-1}$, DPR_HS also has a higher $\mathrm{CV}$ value in convective category, while above the $10 \mathrm{~mm} \mathrm{~h}^{-1}$ it is smaller when compared to the DPR_MS and DPR_NS.

In Fig. 4a, the comparison of PE between the three DPR swath types and the rain gauge is shown. All swath types show obvious systematic deviations that are smaller than that of the rain gauge data, which is consistent with the results in Fig. 3. The peak frequencies (in percentage) of occurrences for DPR_NS and DPR_HS occur at PE below $-50 \%$, whereas the peak frequency for DPR_MS occurs at PE around $-40 \%$. Therefore, the DPR_MS compares better with gauge estimates than the other swath types. Statistical analysis is also conducted with respect to rainfall intensity. The frequencies of underestimation for the three swath types at different intervals of rain intensities are shown in Fig. 4b. All three swath types show the similar trend that the frequency of underestimation increases with precipitation intensity. Moreover, they all show the overestimation, with the frequency of underestimation less than $30 \%$ at precipitation intensity at $0.5-1 \mathrm{~mm} \mathrm{~h}^{-1}$.

Figure $4 \mathrm{c}$ shows the mean percentage error between three DPR swath types and rain gauge. In the range of $0.5-2.5 \mathrm{~mm} \mathrm{~h}^{-1}$, DPR estimates are in general greater than ground-based estimates, while above the $5 \mathrm{~mm} \mathrm{~h}^{-1}$ they are smaller. The satellite estimates are the closest to the ground-based estimates with the smallest mean percentage error when the rainfall rate is between 2.5 and $5 \mathrm{~mm} \mathrm{~h}^{-1}$. Focusing on the differences between three swath types in Fig. 4c, DPR_HS shows good comparison with gauges from 0.5 to $2.5 \mathrm{~mm} \mathrm{~h}^{-1}$. However, DPR_HS estimates are much smaller than those from gauges above the $2.5 \mathrm{~mm} \mathrm{~h}^{-1}$. Comparatively, DPR_MS estimates compare better for the rain rates above the $2.5 \mathrm{~mm} \mathrm{~h}^{-1}$; they are closer to gauge estimates especially between 2.5 and $5 \mathrm{~mm} \mathrm{~h}^{-1}$. In other words, DPR_HS estimates light precipitation better than DPR_MS when compared against gauges, while DPR_MS is superior at higher rain rates.

In Figs. 4d-f, the three DPR swath types have the similar distribution as gauges in the occurrence frequency in different rain-rate intervals, all showing $40 \%$ samples in $1-2.5 \mathrm{~mm} \mathrm{~h}^{-1}$. They tend to overestimate the occurrence for rain rates below
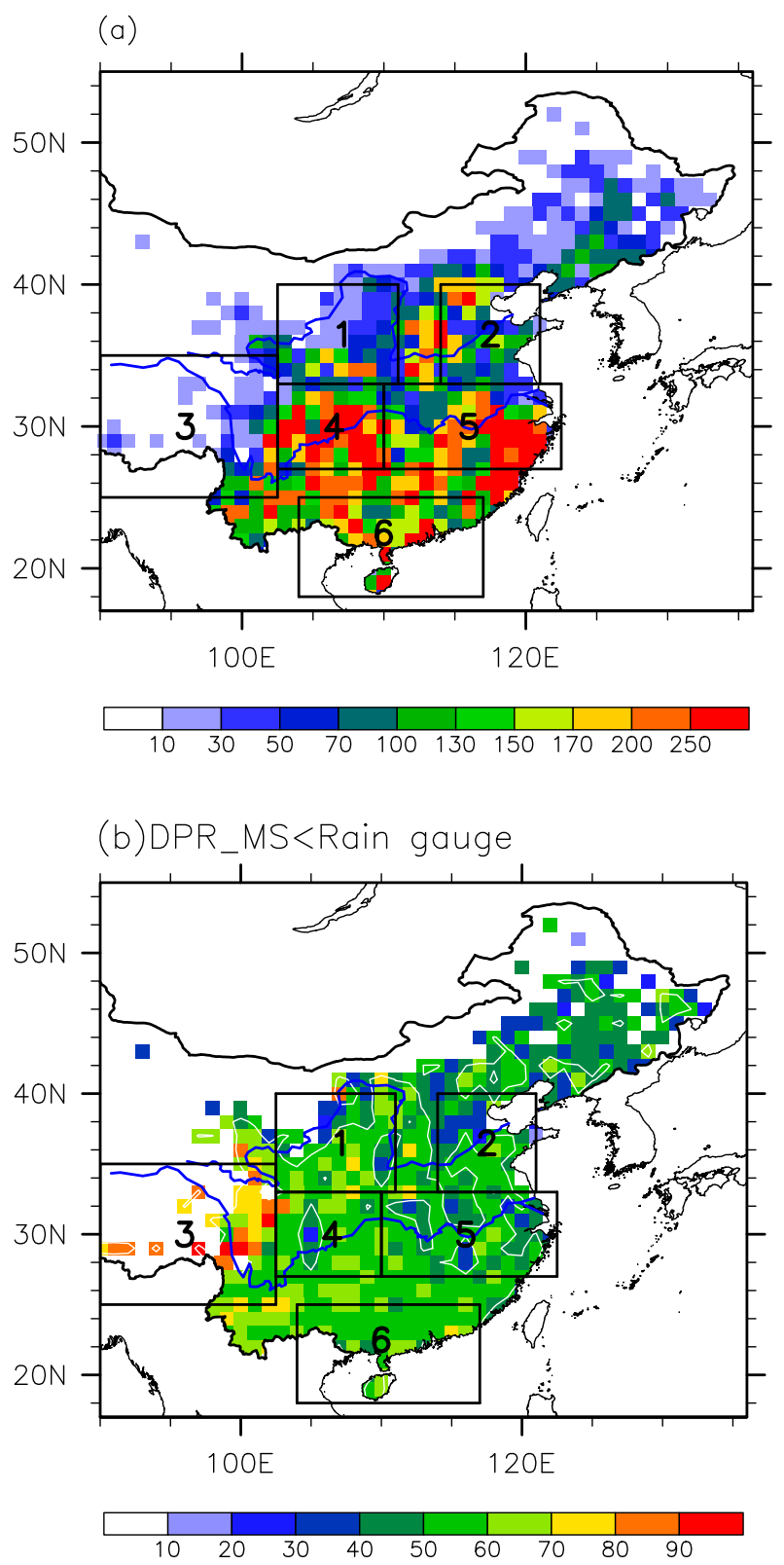

FIG. 5. (a) Spatial distribution of matched samples between DPR_MS estimated surface precipitation products and groundbased rain gauges at $1^{\circ} \times 1^{\circ}$ resolution during the summer from 2014 to 2018 . The six boxes represent 1$)$ Northwest China $\left(33^{\circ}-40^{\circ} \mathrm{N}\right.$, $\left.\left.102.5^{\circ}-111^{\circ} \mathrm{E}\right), 2\right)$ North China Plain $\left(33^{\circ}-40^{\circ} \mathrm{N}, 114^{\circ}-121^{\circ} \mathrm{E}\right)$, 3) Tibetan Plateau $\left(25^{\circ}-35^{\circ} \mathrm{N}, 90^{\circ}-102.5^{\circ} \mathrm{E}\right)$, 4) Sichuan Basin $\left.\left(27^{\circ}-33^{\circ} \mathrm{N}, 102.5^{\circ}-110^{\circ} \mathrm{E}\right), 5\right)$ Yangtze Plain $\left(27^{\circ}-33^{\circ} \mathrm{N}, 110^{\circ}-122.5^{\circ} \mathrm{E}\right)$, and 6) South China $\left(18^{\circ}-25^{\circ} \mathrm{N}, 104^{\circ}-117^{\circ} \mathrm{E}\right)$. (b) The distribution of the occurrence frequency (\%) when the DPR_MS underestimates the rain rates in comparison with rain gauge data. The white line represents the $50 \%$ contour line.

$2.5 \mathrm{~mm} \mathrm{~h}^{-1}$ while underestimate the occurrence of higher rain rates. In addition, the frequency of DPR_HS is much higher (between 0.5 and $1.0 \mathrm{~mm} \mathrm{~h}^{-1}$ ) than the other estimates. In general, the occurrence frequency of DPR_MS 
TABLE 3. The densities of rain gauge for six regions in 2014 and 2018.

\begin{tabular}{lccccc}
\hline \multicolumn{1}{c}{ Regions } & Area $\left(\mathrm{km}^{2}\right)$ & $\begin{array}{c}\text { No. of } \\
\text { gauges }(2014)\end{array}$ & $\begin{array}{c}\text { No. of } \\
\text { gauges }(2018)\end{array}$ & $\begin{array}{c}\text { Density of rain gauges in 2014 } \\
\left(\text { gauges per } 100 \mathrm{~km}^{2}\right)\end{array}$ & $\begin{array}{c}\text { Density of rain gauges in 2018 } \\
\left(\text { gauges per 100 km }{ }^{2}\right)\end{array}$ \\
\hline Northwest China & 594306 & 2172 & 5070 & 0.37 & 0.85 \\
North China Plain & 396404 & 5185 & 6259 & 1.31 & 1.58 \\
Tibetan Plateau & 1089985 & 1253 & 2453 & 0.12 & 0.23 \\
Sichuan Basin & 479972 & 7039 & 8581 & 1.47 & 1.79 \\
Yangtze Plain & 733329 & 10093 & 13513 & 1.38 & 1.84 \\
South China & 452037 & 4273 & 6682 & 0.95 & 1.48 \\
\hline
\end{tabular}

as a function of rain rate exhibits a distribution closest to that of gauges.

\section{b. Evaluation of DPR_MS on different terrain}

As mentioned above, DPR_MS estimates, when compared against gauge estimates, not only had smaller systematic deviations but also exhibited higher CC than DPR_NS and DPR_HS. Therefore, a detailed analysis is carried out to investigate the topography-dependent discrepancies between the DPR_MS and the rain gauge estimates.

Considering the difference of topography and precipitation distribution (Qian and Lin 2005), three latitudinal zones are selected, including six typical geographical regions of China (Fig. 5a), namely, Northwest China $\left(33^{\circ}-40^{\circ} \mathrm{N}, 102.5^{\circ}-111^{\circ} \mathrm{E}\right)$, North China Plain $\left(33^{\circ}-40^{\circ} \mathrm{N}, 114^{\circ}-121^{\circ} \mathrm{E}\right)$, Tibetan Plateau $\left(25^{\circ}-35^{\circ} \mathrm{N}, 90^{\circ}-102.5^{\circ} \mathrm{E}\right)$, Sichuan Basin $\left(27^{\circ}-33^{\circ} \mathrm{N}, 102.5^{\circ}-110^{\circ} \mathrm{E}\right)$, Yangtze Plain $\left(27^{\circ}-33^{\circ} \mathrm{N}, 110^{\circ}-122.5^{\circ} \mathrm{E}\right)$ and South China $\left(18^{\circ}-\right.$ $25^{\circ} \mathrm{N}, 104^{\circ}-117^{\circ} \mathrm{E}$ ). This division method is commonly used in the past studies of precipitation (Zhai et al. 2005). Especially for evaluating satellite precipitation products in China, dividing into small regions is necessary (Guo et al. 2016; Zhao et al. 2018). The spatial density of the rain gauges in these regions is shown in Table 3. The number of gauges in Sichuan Basin and Yangtze Plain is several times of that in Tibetan Plateau. The density of rain gauge is more than or close to 1.0 gauge per $100 \mathrm{~km}^{2}$ in North China Plain, Sichuan Basin, Yangtze Plain, and South China. This is highly dense compared to 0.12 and 0.23 gauges per $100 \mathrm{~km}^{2}$ over Tibetan Plateau in 2014 and 2018, respectively.

The DPR_MS estimates relative to gauges in these typical regions is shown in this section. Figure 5b illustrates the spatial distribution of the occurrence frequency of underestimation for DPR_MS in comparison with gauge observations. The satellite estimates underestimate rainfall rates in most parts of the regions with occurrence frequencies greater than $60 \%$; in Tibetan Plateau the occurrence frequency of underestimation is more than $70 \%$. However, DPR_MS estimates show a larger area of overestimation in the northern part of the North China Plain, with the underestimation frequency of less than $40 \%$.

In Fig. 6, scatterplots between satellite estimated precipitation and rain gauge are shown for the six typical regions. In general, the rain rates in Tibetan Plateau and Northwest China are smaller due to the climatic characteristics, and most of the samples are concentrated between 0.5 and $5 \mathrm{~mm} \mathrm{~h}^{-1}$ (Figs. 6a,g). A comparison of all regions shows that DPR_MS estimates produce more obvious underestimation in Tibetan Plateau. The DPR_MS estimates in Sichuan Basin show the better performance. Meanwhile, the points are more concentrated along the 1-to-1 line with the increase of rain rate (Fig. 6j). However, DPR_MS estimates indicate obvious overestimation in North China Plain. Because most samples belong to stratiform precipitation, the distribution of stratiform scatterplots looks more similar with the total ones. There are obvious differences between different regions in convective precipitation (Figs. 6c,f,i,l,o,r). The DPR_MS underestimates convective precipitation in Sichuan Basin (Fig. 61), Yangtze Plain (Fig. 6o), and South China (Fig. 6r), whereas the convective samples are more dispersed in North China Plain (Fig. 6f). Although there are few convective samples in Tibetan Plateau, these points are well distributed around the diagonal line.

Further analysis is done based on the statistical indicators, which are reported in Table 4, and the best value is bolded. The spatial density of rain gauges in these regions is different (Table 3), it is highly dense in North China Plain, Sichuan Basin, Yangtze Plain, and South China compared to Tibetan Plateau. On the other hand, the higher frequency of precipitation in the southern and eastern parts of China is mainly due to climatic characteristics. These two aspects lead to the number of matched estimates being uneven.

The total precipitation samples have lower ME in Northwest China, while the stratiform samples have lower ME in Yangtze Plain. Comparatively, the ME in North China reaches 0.39 which marked overestimation by DPR_MS. The Tibetan Plateau obtains the lower RMSE not only in total precipitation but also in convective precipitation. However, it shows a general underestimation in Fig. 6g. This phenomenon is mainly caused by the lower sample size and rain rates in Tibetan Plateau. The CC is best for the DPR_MS estimates in Sichuan Basin.

Figure 7 a shows the PE for six regions in comparison with rain gauge. The percentage frequency of occurrence peaked around PE of $\sim-40 \%$ for Sichuan Basin and Northwest China, and the occurrence frequency is less than $10 \%$ of the samples, while the percentage frequency of occurrence peaked around PE of $\sim-60 \%$ for Tibetan Plateau, and the occurrence frequency is above $10 \%$. As shown in Fig. $7 \mathrm{~b}$, the satellite estimates are greater than those of gauges in six regions when the rain rate is from 0.5 to $1 \mathrm{~mm} \mathrm{~h}^{-1}$. Most regions indicate a similar overestimation at precipitation between 1.0 and $2.5 \mathrm{~mm} \mathrm{~h}^{-1}$ except for Tibetan Plateau. With increasing rain rate, the mean percentage error changes from positive to negative, which shows a general underestimation at rain rates greater than $5 \mathrm{~mm} \mathrm{~h}^{-1}$. In particular, the satellite estimates in North China overestimate precipitation between 0.5 and $10 \mathrm{~mm} \mathrm{~h}^{-1}$, which is consistent with the results in 

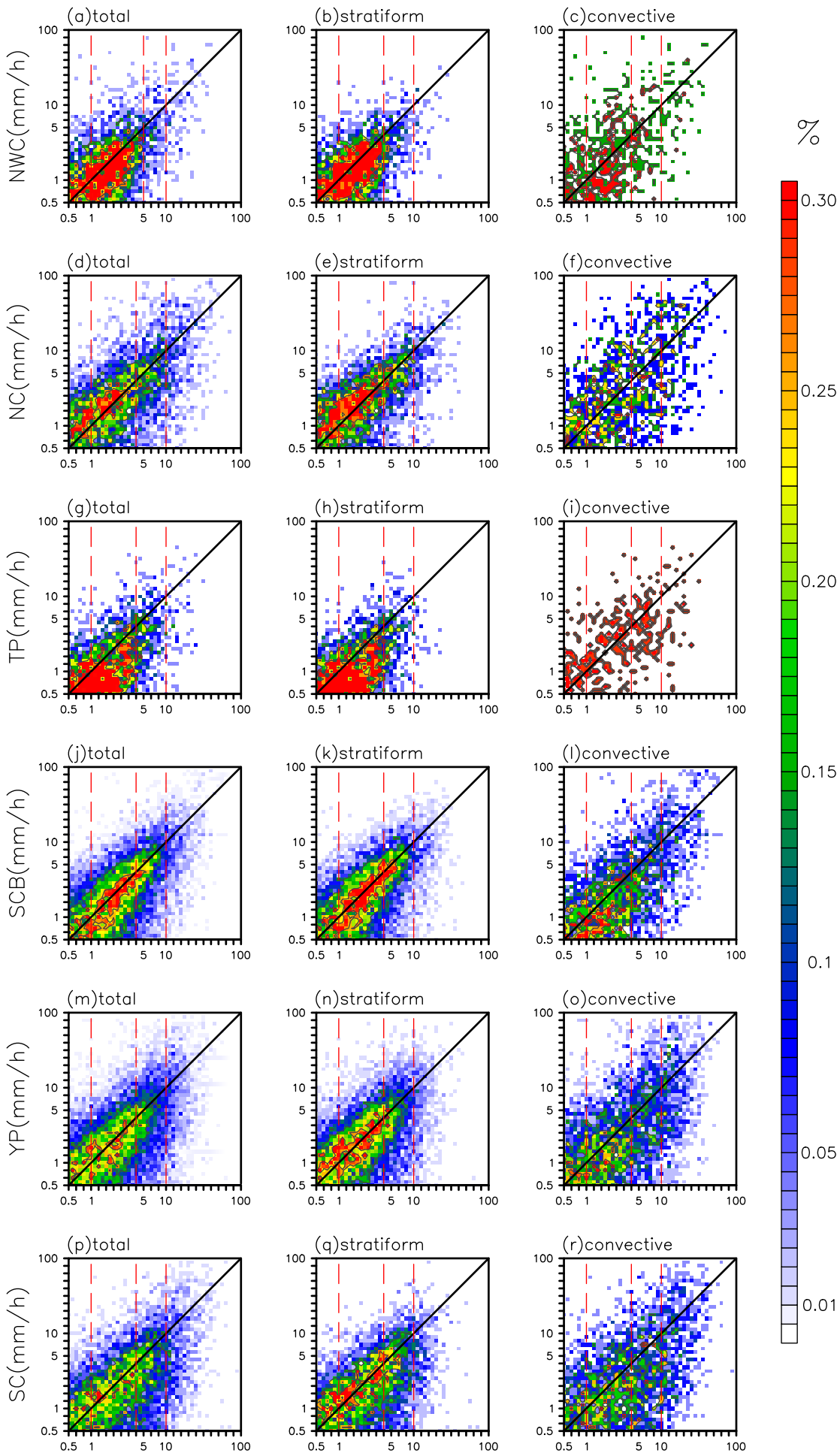

\section{Rain gauge $(\mathrm{mm} / \mathrm{h})$}

FIG. 6. Density scatterplots for the DPR_MS estimated surface precipitation vs ground reference data for the six regions. The six regions are the same as Fig. 5. The left, center, and right columns represent all samples of total, stratiform, and convective precipitation, respectively. The occurrence frequency represents the percentage with respect to the total samples of the number (all samples, stratiform precipitation samples, and convective precipitation samples, respectively) lying in each grid area with an interval of $10^{0.05} \mathrm{~mm} \mathrm{~h}^{-1}$. The color bar indicates the occurrence frequency (\%) of samples lying within each grid area. The black line is the 1:1 line. 
TABLE 4. Statistical indicators of DPR_MS estimated surface precipitation, for the six regions computed with respect to rain gauges. The best value is bolded for each cell.

\begin{tabular}{|c|c|c|c|c|}
\hline & \multirow[b]{2}{*}{ Products } & \multicolumn{3}{|c|}{ Precipitation } \\
\hline & & Total & Stratiform & Convective \\
\hline \multirow[t]{6}{*}{ No. of points } & Northwest China & 3369 & 2691 & 671 \\
\hline & North China Plain & 4699 & 3396 & 1266 \\
\hline & Tibetan Plateau & 2675 & 2321 & 346 \\
\hline & Sichuan Basin & 10900 & 8154 & 2734 \\
\hline & Yangtze Plain & 13807 & 9725 & 4053 \\
\hline & South China & 7586 & 4746 & 2822 \\
\hline \multirow[t]{6}{*}{ Percentage of stratiform or convective (\%) } & Northwest China & $100 \%$ & $79.88 \%$ & $19.92 \%$ \\
\hline & North China Plain & $100 \%$ & $72.27 \%$ & $26.94 \%$ \\
\hline & Tibetan Plateau & $100 \%$ & $86.77 \%$ & $12.93 \%$ \\
\hline & Sichuan Basin & $100 \%$ & $74.81 \%$ & $25.08 \%$ \\
\hline & Yangtze Plain & $100 \%$ & $70.44 \%$ & $29.35 \%$ \\
\hline & South China & $100 \%$ & $62.56 \%$ & $37.20 \%$ \\
\hline \multirow[t]{6}{*}{ Mean error $\left(\mathrm{mm} \mathrm{h}^{-1}\right)$} & Northwest China & -0.04 & -0.29 & 0.95 \\
\hline & North China Plain & 0.39 & -0.05 & 1.60 \\
\hline & Tibetan Plateau & -0.59 & -0.63 & -0.31 \\
\hline & Sichuan Basin & -0.16 & -0.22 & 0.05 \\
\hline & Yangtze Plain & 0.19 & 0.04 & 0.58 \\
\hline & South China & -0.71 & -0.77 & -0.63 \\
\hline \multirow[t]{6}{*}{ Root-mean-square error $\left(\mathrm{mm} \mathrm{h}^{-1}\right)$} & Northwest China & 4.04 & 2.24 & 7.86 \\
\hline & North China Plain & 7.29 & 4.7 & 11.69 \\
\hline & Tibetan Plateau & 3.07 & 2.39 & 5.87 \\
\hline & Sichuan Basin & 5.46 & 3.82 & 8.68 \\
\hline & Yangtze Plain & 6.85 & 4.83 & 10.19 \\
\hline & South China & 7.20 & 4.94 & 9.93 \\
\hline \multirow[t]{6}{*}{ Pearson correlation coefficient } & Northwest China & 0.53 & 0.53 & 0.50 \\
\hline & North China Plain & 0.53 & 0.53 & 0.49 \\
\hline & Tibetan Plateau & 0.49 & 0.43 & 0.46 \\
\hline & Sichuan Basin & 0.57 & 0.55 & 0.58 \\
\hline & Yangtze Plain & 0.46 & 0.43 & 0.46 \\
\hline & South China & 0.46 & 0.40 & 0.46 \\
\hline
\end{tabular}

Fig. 6d. In Figs. 7c-h, the occurrence frequencies with different rain rates from rain gauge and DPR_MS estimates are shown. Over the rain rate intervals, the frequency distribution of Yangtze Plain and North China are closer to that of the gauges with discrepancies less than 5\%. DPR_MS frequency is almost $20 \%$ higher than that of gauges in the Tibetan Plateau when the rain rate is $0.5-1 \mathrm{~mm} \mathrm{~h}^{-1}$.

\section{Conclusions}

In this paper, we evaluated the GPM level-2 DPR precipitation rate estimates at the surface, using dense rain gauge network data over China. The latest GPM products during the summer from 2014 to 2018 are used.

In general, the DPR precipitation estimates for all swath types (DPR_NS, DPR_MS, and DPR_HS) show a prevailing underestimation of rain rates compared to gauges. Relatively, DPR_MS and DPR_NS show better agreement with gauge estimates than DPR_HS. In addition, all three swath types show similar performance for the stratiform precipitation. DPR_HS severely underestimates rain rate for convective precipitation when compared to gauge estimates. Statistical indicators show that the DPR_MS has the lowest ME and highest $\mathrm{CC}$ among the three swath types, and its systematic deviation of PE from gauge estimates is the smallest. We also evaluated DPR products performance for different rain rate intensity intervals. All DPR swath types show obvious overestimation relative to gauges between 0.5 and $1.0 \mathrm{~mm} \mathrm{~h}^{-1}$ and distinct underestimation for precipitation larger than $1.0 \mathrm{~mm} \mathrm{~h}^{-1}$. Furthermore, all DPR swath types show the smallest mean percentage error from 2.5 to $5 \mathrm{~mm} \mathrm{~h}^{-1}$ when compare with the other rain-rate intensities. DPR_HS and DPR_MS show the lowest mean percentage error below and above $2.5 \mathrm{~mm} \mathrm{~h}^{-1}$, respectively. In other words, DPR_HS shows more skills below $2.5 \mathrm{~mm} \mathrm{~h}^{-1}$, while the DPR_MS has the advantage at higher rain rates. Results also show that, compared against gauges, all the estimates tend to overestimate the occurrence of rain rate in the range of $0.5-2.5 \mathrm{~mm} \mathrm{~h}^{-1}$, while they tend to underestimate the occurrence when rain rate is larger than $2.5 \mathrm{~mm} \mathrm{~h}^{-1}$. Comparatively, DPR_MS estimates have the best performance among the three. There are some differences with the studies carried out by Petracca et al. (2018). They found that DPR_NS estimates outperforms the DPR_MS and DPR_HS during the summer season in Italy, while we found that DPR_MS estimates are better than others during the summer in China. In addition, Petracca et al. (2018) revealed that DPR_HS 

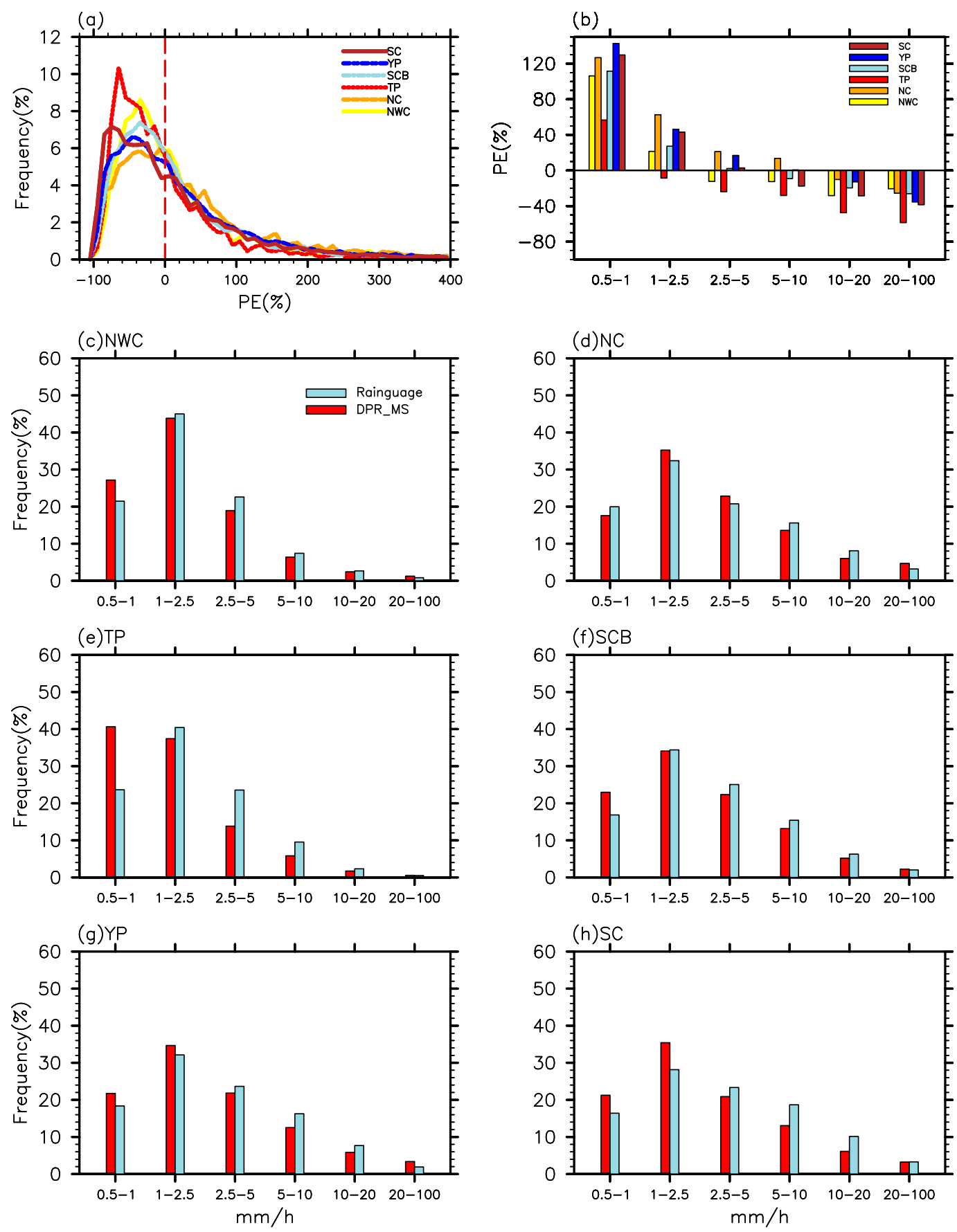

FIG. 7. (a) The PE for DPR_MS estimated surface precipitation in comparison with rain gauge data for the six regions; the interval of PE is $20 \%$ on the horizontal axis. (b) The mean percentage error of the DPR_MS estimates and (c)-(h) the occurrence frequency with different rain rates from DPR_MS and rain gauge. The six regions are the same as Fig. 5.

shows more skills below $1.0 \mathrm{~mm} \mathrm{~h}^{-1}$ while we found the DPR_HS has the advantage below $2.5 \mathrm{~mm} \mathrm{~h}^{-1}$. This phenomenon is mainly caused by the fact that more details for the rain rate intensity intervals were provided in our study.

A deeper investigation was carried out to analyze the DPR_MS's performance over complex terrains of China. The DPR_MS shows an obvious underestimation in the
Tibetan Plateau with a slight overestimation in the North China Plain. Furthermore, the occurrence frequency of underestimation is around $60 \%$ in the most of regions, while it is $70 \%$ in Tibetan Plateau. Compared with the stratiform precipitation, convective estimates of DPR_MS are worse over most of the regions. DPR_MS estimates in Sichuan Basin indicate the better performance, even if the RMSE is lower in 
the Tibetan Plateau and Northwest China due to the smaller sample size and rain rates. The occurrence distributions over rain rate intervals of the satellite estimates are very close to that of rain gauge data in the Yangtze Plain and North China, with errors often below $5 \%$.

Precipitation estimates are the basic products of GPM satellite. This paper assessed the suitability and limitation of GPM level-2 products over China. However, due to its short time in operation, the number of samples used for evaluation is limited in this paper. In the future, more samples are needed to obtain more accurate results. In addition, we will focus on the comparisons of reflectivity and rain drop size distribution in order to explore more details of precipitation.

Acknowledgments. This research was supported by the Second Tibetan Plateau Scientific Expedition and Research (STEP) program (Grant 2019QZKK0105) and the National Key Research and Development Program of China (2016YFA0602100). The 2A-DPR V06 GPM data were downloaded from the Science Team On-Line Request Module (https:/storm-pps.gsfc.nasa.gov/). The authors thank the National Meteorological Information Center of China Meteorological Administration for providing dense rain gauge data. J. Wang's participation is made possible by the in-kind (James E. Ashton Professorship) support from The University of Iowa.

\section{REFERENCES}

Awaka, J., M. Le, V. Chandrasekar, N. Yoshida, T. Higashiuwatoko, T. Kubota, and T. Iguchi, 2016: Rain type classification algorithm module for GPM dual-frequency precipitation radar. J. Atmos. Oceanic Technol., 33, 1887-1898, https://doi.org/10.1175/JTECHD-16-0016.1.

Bhat, G. S., and S. Kumar, 2015: Vertical structure of cumulonimbus towers and intense convective clouds over the South Asian region during the summer monsoon season. J. Geophys. Res. Atmos., 120, 1710-1722, https://doi.org/10.1002/2014JD022552.

Casella, D., G. Panegrossi, P. Sanò, A. C. Marra, S. Dietrich, B. T. Johnson, and M. S. Kulie, 2017: Evaluation of the GPM-DPR snowfall detection capability: Comparison with CloudSat-CPR. Atmos. Res., 197, 64-75, https://doi.org/10.1016/ j.atmosres.2017.06.018.

Gao, J., G. Tang, and Y. Hong, 2017: Similarities and improvements of GPM Dual-Frequency Precipitation Radar (DPR) upon TRMM Precipitation Radar (PR) in global precipitation rate estimation, type classification and vertical profiling. Remote Sens., 9, 1142, https://doi.org/10.3390/rs9111142.

Guo, H., S. Chen, A. Bao, A. Behrangi, Y. Hong, F. Ndayisaba, J. Hu, and P. M. Stepanian, 2016: Early assessment of integrated multi-satellite retrievals for global precipitation measurement over China. Atmos. Res., 176-177, 121-133, https:// doi.org/10.1016/j.atmosres.2016.02.020.

Hamada, A., and Y. N. Takayabu, 2016: Improvements in detection of light precipitation with the Global Precipitation Measurement Dual-Frequency Precipitation Radar (GPM DPR). J. Atmos. Oceanic Technol., 33, 653-667, https://doi.org/10.1175/JTECH-D15-0097.1.

Hence, D. A., and R. A. Houze, 2012: Vertical structure of tropical cyclones with concentric eyewalls as seen by the TRMM Precipitation Radar. J. Atmos. Sci., 69, 1021-1036, https:// doi.org/10.1175/JAS-D-11-0119.1.
Hou, A. Y., and Coauthors, 2014: The Global Precipitation Measurement mission. Bull. Amer. Meteor. Soc., 95, 701-722, https://doi.org/10.1175/BAMS-D-13-00164.1.

Iguchi, T., S. Seto, R. Meneghini, N. Yoshida, J. Awaka, and T. Kubota, 2010: GPM/DPR level-2 algorithm theoretical basis document. NASA Goddard Space Flight Center, 68 pp., http://pps.gsfc.nasa.gov/Documents/ATBD_DPR_ 2015_whole_a.pdf.

L'Ecuyer, T. S., and G. McGarragh, 2010: A 10-year climatology of tropical radiative heating and its vertical structure from TRMM observations. J. Climate, 23, 519-541, https://doi.org/ 10.1175/2009JCLI3018.1.

Lu, X., M. Wei, G. Tang, and Y. Zhang, 2018: Evaluation and correction of the TRMM 3B43V7 and GPM 3IMERGM satellite precipitation products by use of ground-based data over Xinjiang, China. Environ. Earth Sci., 77, 209, https://doi.org/ 10.1007/s12665-018-7378-6.

Ma, L., L. Zhao, L. M. Tian, L. M. Yuan, Y. Xiao, D. F. Zou, and Y. P. Qiao, 2019: Evaluation of the Integrated Multi-Satellite Retrievals for Global Precipitation Measurement over the Tibetan Plateau. J. Mt. Sci., 16, 1500-1514, https://doi.org/ 10.1007/s11629-018-5158-0.

Maghsood, F. F., H. Hashemi, S. H. Hosseini, and R. Berndtsson, 2020: Ground validation of GPM IMERG precipitation products over Iran. Remote Sens., 12, 48, https://doi.org/10.3390/ rs12010048.

Mahmud, M. R., M. Hashim, and M. N. M. Reba, 2017: How effective is the new generation of GPM satellite precipitation in characterizing the rainfall variability over Malaysia? Asia-Pac. J. Atmos. Sci., 53, 375-384, https://doi.org/10.1007/s13143-0170042-3.

Petracca, M., L. P. D’Adderio, F. Porcù, G. Vulpiani, S. Sebastianelli, and S. Puca, 2018: Validation of GPM Dual-Frequency Precipitation Radar (DPR) rainfall products over Italy. J. Hydrometeor., 19, 907-925, https://doi.org/10.1175/JHMD-17-0144.1.

Qian, W., and X. Lin, 2005: Regional trends in recent precipitation indices in China. Meteor. Atmos. Phys., 90, 193-207, https:// doi.org/10.1007/s00703-004-0101-z.

Shen, Y., A. Xiong, Y. Wang, and P. Xie, 2010: Performance of highresolution satellite precipitation products over China. J. Geophys. Res., 115, D02114, https://doi.org/10.1029/2009JD012097.

_, P. Zhao, Y. Pan, and J. Yu, 2014: A high spatiotemporal gaugesatellite merged precipitation analysis over China. J. Geophys. Res., 119, 3063-3075, https://doi.org/10.1002/2013JD020686.

Speirs, P., M. Gabella, and A. Berne, 2017: A comparison between the GPM Dual-Frequency Precipitation Radar and groundbased radar precipitation rate estimates in the Swiss Alps and Plateau. J. Hydrometeor., 18, 1247-1269, https://doi.org/10.1175/ JHM-D-16-0085.1.

Sun, W., Y. Sun, X. Li, T. Wang, Y. Wang, Q. Qiu, and Z. Deng, 2018: Evaluation and correction of GPM IMERG precipitation products over the capital circle in northeast China at multiple spatiotemporal scales. Adv. Meteor., 2018, 4714173, https://doi.org/10.1155/2018/4714173.

Tan, M. L., and Z. Duan, 2017: Assessment of GPM and TRMM precipitation products over Singapore. Remote Sens., 9, 720, https://doi.org/10.3390/rs9070720.

Tang, G., Y. Wen, J. Gao, D. Long, Y. Ma, W. Wan, and Y. Hong, 2017: Similarities and differences between three coexisting spaceborne radars in global rainfall and snowfall estimation. Water Resour. Res., 53, 3835-3853, https://doi.org/10.1002/ 2016WR019961. 
Yu, C., D. Hu, M. Liu, S. Wang, and Y. Di, 2020: Spatio-temporal accuracy evaluation of three high-resolution satellite precipitation products in China area. Atmos. Res., 241, 104952, https:// doi.org/10.1016/j.atmo sres.2020.104952.

Yuan, F., L. Zhang, K. W. W. Win, L. Ren, C. Zhao, Y. Zhu, S. Jiang, and Y. Liu, 2017: Assessment of GPM and TRMM multi-satellite precipitation products in streamflow simulations in a data-sparse mountainous watershed in Myanmar. Remote Sens., 9, 302, https://doi.org/10.3390/rs9030302.

Zhai, P., X. Zhang, H. Wan, and X. Pan, 2005: Trends in total precipitation and frequency of daily precipitation extremes over China. J. Climate, 18, 1096-1108, https://doi.org/10.1175/ JCLI-3318.1.
Zhang, A., and Y. Fu, 2018: The structural characteristics of precipitation cases detected by dual-frequency radar of GPM satellite. Chin. J. Atmos. Sci., 42, 33-51, https://doi.org/10.3878/ j.issn.1006-9895.1705.16220.

Zhang, S., D. Wang, Z. Qin, Y. Zheng, and J. Guo, 2018: Assessment of the GPM and TRMM precipitation products using the rain gauge network over the Tibetan Plateau. J. Meteor. Res., 32, 324-336, https://doi.org/10.1007/s13351018-7067-0.

Zhao, H., B. Yang, S. Yang, Y. Huang, G. Dong, J. Bai, and Z. Wang, 2018: Systematical estimation of GPM-based global satellite mapping of precipitation products over China. Atmos. Res., 201, 206-217, https://doi.org/10.1016/j.atmosres.2017.11.005. 